\title{
Suco composto de milho: formulação e caracterização físico-química
}

O objetivo deste estudo foi de formular e realizar as análises físico-químicas do suco de milho produzido no município de Parauapebas/PA. Foi realizada caracterização física de 100 espigas de milho através das medidas de peso das espigas, peso da polpa, peso da casca, rendimento da polpa, comprimento e diâmetro. Para obtenção dos sucos de milho, foram elaboradas as seguintes formulações: suco de milho natural (F1: $21 \%$ de grãos: $33 \%$ de água); suco de milho com leite de soja (F2: $21 \%$ de grãos: $33 \%$ de leite de soja); suco de milho com leite bovino (F3: $21 \%$ de grãos: $33 \%$ de leite bovino). Para caracterização físico-química, foram realizadas as análises de pH, acidez total titulável, teor de sólidos solúveis, umidade, cinzas, lipídios, proteínas, carboidratos e valor energético total. Os resultados das análises físico-químicas dos produtos artesanais foram submetidos à análise de variância através do teste de Tukey a $5 \%$ de carboidratos e valor energético total. Os resultados das análises físico-químicas dos produtos artesanais foram submetidos à análise de variância através do teste de Tukey a $5 \%$ de
probabilidade. Em relação à caracterização física das espigas do híbrido duplo BR 205 Embrapa, os parâmetros avaliados comprimento médio das espigas com palha (32,76 cm) e sem palha $(20,88 \mathrm{~cm})$, diâmetro médio da base da espiga com palha $(5,83 \mathrm{~cm})$ e sem palha $(4,72 \mathrm{~cm})$, o diâmetro médio do meio da espiga com palha $(5,37 \mathrm{~cm})$ e sem palha $(4,62 \mathrm{~cm})$, já o diâmetro da ponta da espiga com palha $(4,05 \mathrm{~cm})$ e sem palha $(3,63 \mathrm{~cm})$. Quanto aos valores obtidos para o peso médio das espigas, com palha $(352,36 \mathrm{~g})$ e sem palha $(225,40 \mathrm{~g})$, e rendimento dos grãos por espiga (133,50 g) estão próximos aos dos valores relatados na literatura. Os teores médios de cinzas, lipídios, proteínas, carboidratos e valor energético total, obtidos para o milho, estão próximos aos estabelecidos pela Tabela Brasileira de Composição de Alimentos. Através dos resultados físico-químicos se observou que os sucos de leite possuem maior valor nutriciona pelos provadores do que o suco natural e o suco com soja. De acordo com os resultados obtidos, os produtos podem se tornar uma opção de aproveitamento do milho pelo Centro Tecnológico de Agricultura Familiar, além de uma fonte alternativa de geração de renda aos agricultores familiares do município de Parauapebas/PA.

Palavras-chave: Composição; Matérias-Primas; Agricultura Familiar.

\section{Corn compound juice: formulation and physico-chemical characterization}

\begin{abstract}
The objective of this study was to formulate and perform physical-chemical analyses of the corn juice produced in the municipality of Parauapebas/PA. A physical characterization of 100 ears of corn was performed by measuring the weight of the ears, weight of the pulp, weight of the shell, pulp yield, length and diameter. To obtain corn juice, the following formulations were prepared: natural corn juice (F1: $21 \%$ grain: $33 \%$ water); corn juice with soymilk (F2: $21 \%$ grain: $33 \%$ soymilk); corn juice with bovine milk (F3: $21 \%$ grain: $33 \%$ bovine milk). For physicalchemical characterization, analyses of $\mathrm{pH}$, total titratable acidity, content of soluble solids, humidity, ashes, lipids, proteins, carbohydrates and total energy value were performed. The results chemical characterization, analyses of $\mathrm{pH}$, total titratable acidity, content of soluble solids, humidity, ashes, lipids, proteins, carbohydrates and total energy value were performed. The results
of the physical-chemical analysis of the handmade products were submitted to analysis of variance using the Tukey test at $5 \%$ probability. Regarding the physical characterization of the double hybrid BR 205 Embrapa ears, the parameters evaluated were the average length of the ears with straw $(32.76 \mathrm{~cm})$ and without straw $(20.88 \mathrm{~cm})$, average diameter of the base of the ear with straw $(5,83 \mathrm{~cm})$ and without straw $(4.72 \mathrm{~cm})$, the middle diameter of the ear with straw $(5.37 \mathrm{~cm})$ and without straw $(4.62 \mathrm{~cm})$, the diameter of the tip of the ear with straw $(4.05$ $\mathrm{cm})$ and without straw $(3.63 \mathrm{~cm})$. The values obtained for the average weight of the ears, with straw $(352.36 \mathrm{~g})$ and without straw $(225.40 \mathrm{~g})$, and grain yield per ear $(133.50 \mathrm{~g})$ are close to the values reported in the literature. The average contents of ashes, lipids, proteins, carbohydrates and total energy value obtained for corn are close to those established by the Brazilian Table of Food Composition. Through the physical-chemical results it was oberved that milk juices have higher nutritional value by tasters than natural juice and juice with soy. According to the results obtained, the products an become an option for the use of obm by the Family Farming Technolog Centre besides being an alternative source of income generation for family antion for the use of corn by the Family Farming Technology Centre, besides bamily farmers in the municipality of Parauapebas/PA.
\end{abstract}

Keywords: Composition; Raw Materials; Family Farming.

Topic: Experimentação Agrícola

Reviewed anonymously in the process of blind peer.
Rodrigo de Souza Mota

Universidade Federal Rural da Amazônia, Brasil http://lattes.cnpq.br/0329344212994088

rodrigodmota@gmail.com

João Paixão dos Santos Neto

Instituto Nacional de Investigação Agrária e

Veterinária, Brasil

http://lattes.cnpq.br/2828947517814190

joaopaixaoneto@gmail.com

Igor Vinícius de Oliveira (iD

Universidade Federal do Sul e Sudeste do Pará, Brasil

http://lattes.cnpq.br/1133025899150852

http://orcid.org/0000-0003-4218-5587

igor.oliveira@unifesspa.edu.br

\section{Clenes Cunha Lima (iD) \\ Universidade Federal Rural da Amazônia, Brasil \\ http://lattes.cnpq.br/6304892315723683 http://orcid.org/0000-0001-8406-9723 clenes.cunha@ufra.edu.br \\ Vicente Filho Alves Silva (iD \\ Universidade Federal Rural da Amazônia, Brasil \\ http://lattes.cnpq.br/6408302249362919 http://orcid.org/0000-0003-2396-6986 \\ vicente.silva@ufra.edu.br \\ José Nilton da Silva (iD) \\ Universidade Federal Rural da Amazônia, Brasil \\ http://lattes.cnpq.br/1354740041680681 http://orcid.org/0000-0003-0298-9126 agro.jose.nilton@gmail.com}

Josiane Pereira da Silva
Universidade Federal Rural da Amazônia,
Brasil
http://lattes.cnpq.br/0459747956580928
$\frac{\text { http://orcid.org/0000-0002-3121-7072 }}{\text { josi19pereira@hotmail.com }}$
Claudete Rosa Silva
Universidade Federal Rural da Amazônia,
Brasil
http://lattes.cnpq.br/5005233180543061
http://orcid.org/0000-0001-5063-8932
claudete.silva@ufra.edu.br
Fábio Israel Martins Carvalho@D
Universidade Federal Rural da Amazônia,
Brasil
http://lattes.cnpq.br/8221002637257793
http://orcid.org/0000-0002-8995-2141
fabioimc@yahoo.com.br

Priscilla Andrade Silva (iD)

Universidade Federal Rural da Amazônia, Brasil

http://lattes.cnpq.br/766688704180671 http://orcid.org/0000-0002-2774-3192 prisciandra@yahoo.com.br

\section{Referencing this:}

MOTA, R. S.; SANTOS NETO, J. P.; OLIVEIRA, I. V.; LIMA, C. C.; SILVA, V. F. A.; SILVA, J. N.; SILVA, J. P.; SILVA, C. R.; CARVALHO, F. I. M.; SILVA, P. A.. Suco composto de milho: formulação e caracterização físicoquímica. Revista Ibero Americana de Ciências Ambientais, v.11, n.3, p.32-43, 2020. DOI: http://doi.org/10.6008/CBPC21796858.2020 .003 .0004

DOI: 10.6008/CBPC2179-6858.2020.003.0004

6858.2020.003.0004 


\section{INTRODUÇÃO}

O milho (Zea mays L.) é um dos principais cereais cultivados no mundo, seguido do trigo e do arroz (VASCONCELOS et al., 2013), considerado uma das culturas mais importantes mundialmente do ponto de vista econômico e social (MARTIN et al., 2017). A área de plantio brasileira é de 14,7 milhões de hectares, a qual produz cerca de 58,7 milhões de toneladas, tornando o Brasil o terceiro maior produtor mundial. A área cultivada no Estado do Pará atingiu 1.149.309 hectares, gerando uma produção de mais de 9,1 milhões de toneladas, com valor estimado em torno de $\mathrm{R} \$ 5,4$ bilhões, representando cerca de $27 \%$ do PIB agropecuário do Estado.

O grão de milho, conhecido botanicamente como uma cariopse, é formado por quatro principais estruturas físicas: endosperma, gérmen, pericarpo e ponta, as quais diferem em composição química e também na organização dentro do grão. 0 endosperma representa aproximadamente $83 \%$ do peso seco do grão, constituindo principalmente de amido (88\%), organizado na forma de grânulos. No endosperma estão também presentes as proteínas de reserva (8\%) do tipo prolaminas, chamadas zeínas. No endosperma, especificamente, na camada de aleurona e no endosperma vítreo, estão presentes os carotenoides, substâncias lipídicas que conferem a cor aos grãos de milho. 0 gérmen representa $11 \%$ do grão de milho e concentra quase a totalidade dos lipídeos (óleo e vitamina E) (83\%) e dos minerais (78\%) do grão, além de conter quantidades importantes de proteínas (26\%) e açúcares (70\%). O pericarpo representa, em média, 5\% do grão, sendo a estrutura que protege as outras estruturas do grão da elevada umidade do ambiente, insetos e microrganismos (PAES et al., 2008).

A produção do milho em várias regiões do Brasil está diretamente ligada a agricultura familiar, e é sempre lembrada por sua importância na produção de alimentos, especialmente voltada para o consumo interno, ou seja, concentra mais nas funções de caráter social do que as econômicas, tendo em vista sua menor produtividade e incorporação tecnológica (STRIEDER, 2006).

O milho é importante para o comércio nacional por ser típico de determinadas regiões, utilizado nas refeições, em épocas festivas e culturais no preparo de derivados, além de ser uma alternativa de grande valor econômico para médios e grandes agricultores, responsáveis pela inserção do produto no mercado (FAO, 2018). A demanda pelo produto in natura após cozimento da espiga, ou o preparo de pratos típicos, como: pamonha, curau, bolos, sorvetes e outros, possuem maior valor de comercialização (EMBRAPA, 2009).

O presente estudo teve como finalidade desenvolver diferentes formulações artesanais de suco de milho (sucos de milho, natural, com leite e com soja) e avaliar as características físico-químicas dos produtos, produzidos a partir dos grãos de milho híbrido duplo BR 205 Embrapa, cultivados pelo Centro Tecnológico de Agricultura Familiar do município de Parauapebas/PA.

\section{METODOLOGIA}

\section{Material}

As espigas de milho do cultivar do tipo híbrido duplo BR 205 Embrapa, desenvolvida pela Empresa 
Brasileira de Pesquisa Agropecuária (EMBRAPA) foram coletadas no Centro Tecnológico de Agricultura

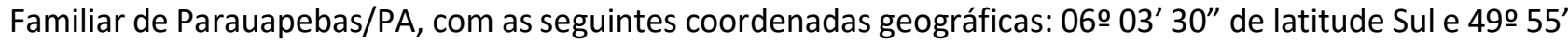
$15^{\prime \prime}$ de longitude a Oeste colhidos aos 3 meses após plantio.

Para a produção dos sucos de milho (natural, com leite soja e com leite bovino) foram utilizadas as seguintes matérias-primas: leite de soja, leite bovino e açúcar, comercializados nos supermercados de Parauapebas/PA e o milho coletado no CETAF (Centro Tecnológico de Agricultura Familiar de Parauapebas/PA).

\section{Métodos}

Foram elaborados os produtos, suco de milho natural, suco de milho com leite de soja, suco de milho com leite bovino, na Universidade Federal Rural da Amazônia, no Campus de Parauapebas, Pará, localizada nas coordenadas geodésicas $49^{\circ} 51^{\prime} 19^{\prime \prime} \mathrm{W}$ latitude, $06^{\circ} 12^{\prime} 58^{\prime \prime} \mathrm{S}$ longitude, com altitude de $197 \mathrm{~m}$ com o auxílio do GPS portátil (Modelo eTrex 10, Marca Garmin), assim como todas as análises físico-químicas. 0 período de realização do trabalho foi de março a julho de 2018. Para as formulações dos sucos de milho natural, suco de milho com leite de soja e suco de milho com leite bovino, foram realizados vários testes com diferentes concentrações de cada matéria-prima empregada.

\section{Caracterização física e rendimento das espigas de milho}

Após a coleta das espigas, foram realizadas uma amostra aleatória contendo 100 espigas para a caracterização física. Este procedimento consistiu na determinação das medidas de peso das espigas (PE), peso dos grãos (PG), peso da palha (PP) e avaliação do diâmetro e comprimento das espigas (ADCE), com auxílio de um paquímetro manual metálico $300 \mathrm{~mm}$ (Marca Vonder) com precisão de 0,01 mm e uma trena. O rendimento dos grãos de milho foi realizado pela separação dos grãos utilizando uma faca inox (Marca Tramontina), palha manualmente e os rendimentos foram determinados através de suas respectivas massas, com auxílio de balança semi-analítica (Modelo ARD110, Marca OHAUS Adventurer).

\section{Processo de obtenção dos grãos do milho}

As espigas sem a palha selecionadas foram lavadas, sanitizadas por imersão em solução com hipoclorito de sódio ( $\mathrm{NaClO}$ ) $(200 \mathrm{mg} / \mathrm{L}$ ) durante 15 minutos e novamente imersos em água por 15 minutos, separadamente. Em seguida, as amostras dos grãos foram manualmente separadas das espigas e embaladas em sacos plásticos de polietileno de $1 \mathrm{Kg}$, congeladas e armazenadas a $-20^{\circ} \mathrm{C}$ para serem utilizadas nas análises físico-químicas do processamento do milho.

\section{Processamento dos produtos de milho}

Foram elaboradas as seguintes formulações: suco de milho natural (F1: 21\% de grãos: 33\% de água); suco de milho com leite de soja (F2: $21 \%$ de grãos: $33 \%$ de leite de soja); suco de milho com leite bovino (F3: 21\% de grãos: 33\% de leite bovino). Em seguida, as misturas foram homogeneizadas por 5 minutos, sobre 
vigorosa agitação e filtradas.

Para as formulações dos sucos (F1, F2 e F3) foi acrescida em função do teor de sólidos solúveis, segundo o cálculo, a quantidade de açúcar suficiente para elevar o teor de sólidos para 20Brix por balanço de massa. Os sucos foram coccionados a $100^{\circ} \mathrm{C}$ por $30 \mathrm{~min}$, seguidos de resfriamento a $25^{\circ} \mathrm{C}$ e novamente homogeneizado por 5 min em seguida filtrados e pasteurizados $\left(90^{\circ} \mathrm{C}\right.$ por 30 segundos). Após, foram envasados e armazenados sob refrigeração a $8^{\circ} \mathrm{C}$ até o momento das análises físico-químicas.

Foi calculado a quantidade de sacarose suficiente para elevar o teor de sólidos solúveis dos sucos para $20^{\circ} \mathrm{Brix}$, utilizando-se o cálculo de balanço de massa a seguir: $\mathrm{Mg} \times{ }^{\circ} \mathrm{Brixg}+\mathrm{Ma} \times{ }^{\circ} \mathrm{Brixa}=\mathrm{Mprod} . \mathrm{x}$ ${ }^{\circ}$ Brixprod., onde: $\mathrm{Mg}=$ massa dos grãos, ${ }^{\circ}$ Brixg $={ }^{\circ}$ Brix dos grãos, $\mathrm{Ma}=$ massa de açúcar, ${ }^{\circ}$ Brixa $={ }^{\circ}$ Brix do açúcar, $\mathrm{Mp}=$ massa do produto, ${ }^{\circ}$ Brixp $={ }^{\circ}$ Brix do produto.

\section{Caracterização físico-químicas das matérias dos grãos de milho e dos produtos elaborados}

Todas as seguintes análises foram realizadas em triplicata $(n=3)$ nos grãos de milho e sucos elaborados: pH: determinado em potenciômetro (Marca Hanna Instruments, Modelo HI9321), de acordo com o método 981.12 da AOAC (1997); Acidez total titulável (ATT): realizada por titulometria com solução de hidróxido de sódio 0,1 $\mathrm{N}$ até a primeira coloração rosa persistente por aproximadamente 30 segundos, e fator de conversão do ácido cítrico foi de 64,02 (AOAC, 1997); Sólidos solúveis totais (SST): foram quantificados nas amostras, segundo AOAC (1997); Umidade: determinada por gravimetria, em estufa (Marca Tecnal, Modelo TE - 395), de acordo com o método 920.151 da AOAC (1997); Cinzas: as amostras foram incineradas em forno tipo mufla a $550^{\circ} \mathrm{C}$, de acordo com o método 930.05 da AOAC (1997); Proteínas: foram determinadas em um espectrofotômetro do tipo UV-Visível (Marca Bioespectro, Modelo SP-220) de acordo com Método do Biureto descrito por Layne (1957); Lipídios: determinado através da extração com mistura de solventes a frio, método de Bligh et al. (1959); Carboidratos: foi calculado por diferença, segundo Resolução $n^{\circ} 360$ de 23 de dezembro de 2003 (ANVISA, 2003). Carboidratos (\%): [100 - (\% umidade + \% proteína + \% lipídios + \% cinzas)]; Valor energético total (VET): foi estimado (kcal/100g) utilizando-se os fatores de conversão de Atwater: $4 \mathrm{kcal} / \mathrm{g}$ para carboidratos e proteínas e $9 \mathrm{kcal} / \mathrm{g}$ para lipídios segundo Anderson et al. (1988) e a Resolução ${ }^{\circ} 360$ de 23 de dezembro de 2003 (ANVISA, 2003).

\section{Análise estatística}

Os resultados das análises físicas das espigas, físico-química dos grãos de milho foram analisados por estatística descritiva utilizando-se medidas de tendência central (média) e de variabilidade de dados (desviopadrão). Já os resultados da análises físico-químicas dos sucos de milho elaborados foram avaliados através das médias submetidas à análise de variância e quando apresentaram diferenças foram comparadas pelo teste de Tukey a $5 \%$ de $(p<0,05)$ probabilidade, utilizando-se o software SAS ${ }^{\circledR}$ versão 9.4 (SAS INSTITUTE, 2013). 


\section{RESULTADOS}

\section{Caracterização física das espigas de milho}

A caracterização física e os rendimentos médios das espigas de milho utilizadas no estudo podem ser observados nas Tabelas 1 e 2 respectivamente.

Tabela 1: Caracterização física das espigas de milho.

\begin{tabular}{|l|l|}
\hline Determinações físicas & Espigas (Média \pm D.P) \\
\hline Comprimento das espigas c/ palha (cm) & $32,76 \pm 3,51$ \\
\hline Comprimento das espigas despalhadas (cm) & $20,88 \pm 2,10$ \\
\hline Diâmetro da base das espigas c/ palha (cm) & $5,83 \pm 0,36$ \\
\hline Diâmetro da base das espigas despalhadas (cm) & $4,72 \pm 0,34$ \\
\hline Diâmetro do meio das espigas c/ palha (cm) & $5,37 \pm 0,62$ \\
\hline Diâmetro do meio das espigas despalhadas (cm) & $4,62 \pm 0,25$ \\
\hline Diâmetro da ponta das espigas c/ palha (cm) & $4,05 \pm 0,62$ \\
\hline Diâmetro da ponta das espigas despalhadas (cm) & $3,63 \pm 0,40$ \\
\hline Espigas com palha (g) & $352,37 \pm 48,56$ \\
\hline Espigas despalhadas (g) & $225,40 \pm 33,79$ \\
\hline Palha das espigas (g) & $121,86 \pm 32,25$ \\
\hline Peso dos grãos por espigas (g) & $133,50 \pm 32,67$ \\
\hline
\end{tabular}

Análise estatística descritiva, os valores representam a média \pm desvio padrão $(n=100)$.

Tabela 2: Rendimento das espigas de milho avaliadas.

\begin{tabular}{|c|c|c|}
\hline Rendimento & Espigas & Peso das espigas (\%) \\
\hline Espigas com palha (kg.espigas ${ }^{-1}$ ) & 35,236 & 100 \\
\hline Espigas despalhadas (kg.espigas ${ }^{-1}$ ) & 22,540 & 63,97 \\
\hline Palha das espigas (kg.espigas ${ }^{-1}$ ) & 12,186 & 34,58 \\
\hline Peso dos grãos das espigas (kg.espigas ${ }^{-1}$ ) & 13,335 & 37,84 \\
\hline
\end{tabular}

\section{Caracterização físico-química dos grãos de milho}

Na Tabela 3 podem ser visualizados os parâmetros físico-químicos avaliados nos grãos de milho utilizados nas formulações dos sucos de milho.

Tabela 3: Caracterização físico-química dos grãos de milho.

\begin{tabular}{|l|l|}
\hline \multirow{2}{*}{ Determinações } & Matéria-prima \\
\cline { 2 - 2 } & Grão de milho (Média \pm D.P) \\
\hline pH & $6,68 \pm 0,29$ \\
\hline SST (oBrix)* & $6,10 \pm 0,10$ \\
\hline ATT (g/100g ácido málico)* & $0,49 \pm 0,07$ \\
\hline Umidade (g/100g) & $64,38 \pm 1,61$ \\
\hline Cinzas (g/100g)* & $0,75 \pm 0,03$ \\
\hline Lipídios (g/100g)* & $1,55 \pm 0,17$ \\
\hline Proteínas (g/100g)* & $4,59 \pm 0,40$ \\
\hline Carboidratos (g/100g)* & $28,72 \pm 1,51$ \\
\hline VET (kcal/100g) & 147,19 \\
\hline
\end{tabular}

SST - Sólidos solúveis totais. ATT - Acidez total titulável. VET - Valor Energético Total. ${ }^{*}$ Resultados em base úmida. Análise estatística descritiva, os valores representam a média \pm desvio padrão de três replicatas $(n=3)$.

\section{Caracterização físico-química dos sucos de milho}

Os valores médios obtidos na caracterização físico-química dos sucos de milho podem ser observados na Tabela 4. 
Tabela 4: Caracterização físico-químicas dos sucos de milho formulados.

\begin{tabular}{|l|l|l|l|l|l|l|}
\hline \multirow{2}{*}{ Determinações } & \multicolumn{5}{|l|}{ Suco de Milho } & \\
\cline { 2 - 7 } & F1 (33\% Água) & F2 (33\% Soja) & F3 (33\% Leite) & DMS & $F_{\text {calc. }}$ & CV \\
\hline pH & $6,80 \pm 0,02^{\mathrm{b}}$ & $6,73 \pm 0,03^{\mathrm{b}}$ & $6,90 \pm 0,03^{\mathrm{a}}$ & 0,0663 & $31,63^{*}$ & 0,3884 \\
\hline SST (oBrix) $)^{* *}$ & $14,00 \pm 0,50^{\mathrm{b}}$ & $14,83 \pm 0,29^{\mathrm{b}}$ & $18,33 \pm 0,29^{\mathrm{a}}$ & 0,9336 & $114,20^{*}$ & 2,3703 \\
\hline ATT (g/100g ác. málico) & $0,43 \pm 0,08^{\mathrm{c}}$ & $0,99 \pm 0,04^{\mathrm{a}}$ & $0,68 \pm 0,04^{\mathrm{b}}$ & 0,0718 & $287,41^{*}$ & 4,0833 \\
\hline Umidade (g/100g) & $82,62 \pm 1,07^{\mathrm{a}}$ & $80,98 \pm 0,05^{\mathrm{b}}$ & $79,66 \pm 0,07^{\mathrm{c}}$ & 0,8459 & $57,87^{*}$ & 0,4163 \\
\hline Cinzas (g/100g) & $0,76 \pm 0,01^{\mathrm{a}}$ & $0,58 \pm 0,01^{\mathrm{c}}$ & $0,67 \pm 0,02^{\mathrm{b}}$ & 0,0323 & $145,80^{*}$ & 1,9268 \\
\hline Lipídios (g/100g) & $0,57 \pm 0,13^{\mathrm{c}}$ & $1,65 \pm 0,10^{\mathrm{b}}$ & $1,96 \pm 0,09^{\mathrm{a}}$ & 0,2106 & $201,93^{*}$ & 5,9107 \\
\hline Proteínas (g/100g) & $0,51 \pm 0,07^{\mathrm{c}}$ & $6,35 \pm 0,56^{\mathrm{b}}$ & $7,11 \pm 0,79^{\mathrm{a}}$ & 0,2773 & $3196,92^{*}$ & 2,3756 \\
\hline Carboidratos (g/100g) & $15,46 \pm 1,01^{\mathrm{a}}$ & $10,42 \pm 0,61^{\mathrm{b}}$ & $10,59 \pm 0,71^{\mathrm{b}}$ & 0,8899 & $194,77^{*}$ & 2,9218 \\
\hline VET (kcal/100g) & 69,01 & 81,93 & 88,44 & & & \\
\hline
\end{tabular}

SST - Sólidos solúveis totais, ATT - Acidez total titulável e VET - Valor Energético Total. ${ }^{* *}$ Resultados em base úmida. Os valores representam a média \pm desvio padrão de três replicatas $(n=3)$. DMS - Diferença mínima significativa; médias seguidas pela mesma letra na mesma linha não diferem estatisticamente entre si pelo teste de Tukey ao nível de $5 \%$ de probabilidade; ns - não significativo; * - significativo ao nível de $5 \%$ de probabilidade. CV - Coeficiente de variação experimental;

\section{DISCUSSÃO}

Na Tabela 1 estão dispostas as características físicas das espigas de milho. Perfeito et al. (2017) analisaram o comprimento das espigas com palha $(29,83 \mathrm{~cm})$ e o comprimento das espigas despalhadas $(30,88 \mathrm{~cm})$ de milho doce submetido ao parcelamento de fertirrigação nitrogenada, possivelmente a razão da diferença dos valores encontrada nesse estudo. Entretanto, quando foi avaliado o comprimento das espigas despalhadas, Perfeito et al. (2017) obtiveram um índice que variou entre 19,78 e 20,95 cm. Santana (2012) utilizou a fertilização organomineral foliar em milho e obteve valores inferiores para o comprimento do milho, entre $(13,51$ e $15,68 \mathrm{~cm})$.

O diâmetro do milho com palha, apresentou na base $(5,83 \mathrm{~cm})$, no meio $(5,37 \mathrm{~cm})$ e na ponta $(4,05$ $\mathrm{cm})$. Já, para o diâmetro do milho despalhado, base $(4,72 \mathrm{~cm})$, meio $(4,62 \mathrm{~cm})$ e ponta $(3,63 \mathrm{~cm})$. Oliveira et al. (2006) encontraram para milhos híbridos valores médios de 4,3 cm. Possivelmente isso ocorreu, devidas às diferenças climáticas da região do estudo.

Para as indústrias, para uma maior eficiência das máquinas degranadoras e maior rendimento industrial, o comprimento das espigas deve ser superior a $15 \mathrm{~cm}$ e o diâmetro maior que $3,0 \mathrm{~cm}$ (BARBIERI et al., 2005). Logo, as médias observadas estão dentro do exigido pela indústria. Os valores dos pesos de espigas com palhas e espigas despalhas (Tabela 1). Pinho (2008) utilizou dois diferentes sistemas de cultivo, o convencional e o orgânico, além de quatro cultivares de milhos diferentes (AG 1051, BR 106, SWB 551 e VIVI). A cultivar AG 1051 que obteve a maior média tanto no sistema convencional (420,20 g) como no sistema orgânico $(300,10 \mathrm{~g})$.

Com relação ao peso das espigas despalhadas (Tabela 1), quando comparado aos valores observados por Pinho (2008), foram observadas diferenças. No sistema de cultivo convencional, a cultivar AG 1051 permaneceu com a média superior (275,10 g) ao do cultivar híbrido duplo BR 205 Embrapa (225,40 g). Na avaliação do peso médio de grãos por espigas, Paes et al. (2008) no seu estudo com milho híbrido doce, obtiveram valores médios do peso de grãos por espigas que variaram de 66,60 a 76,76 g. Pinho (2008) encontraram em cultivos convencional e orgânico para o peso médio de grãos por espigas de 93,77 a 152,78 
g, respectivamente. Esta diferença pode ser explicada pelo genótipo e a época de colheita serem diferentes.

O mercado exige cultivares que apresentem melhor rendimento de palha para a produção de derivados do milho verde, como é o caso da pamonha (PEREIRA FILHO et al., 2002). A cultivar AG 1051 apresentou valor médio do peso da palha de $146,0 \mathrm{~g}$, valor este superior quando comparado ao do cultivar híbrido duplo BR 205 da Embrapa (121,86 g) avaliado.

O rendimento é um dos pontos primordiais da implantação de uma cultura. Santos et al. (2005), no sistema orgânico, referem que a produção de milho foi menor que a esperada em sistema convencional, no primeiro ano de cultivo. A mudança de uma área de sistema convencional para o sistema orgânico, precisa de um intervalo de dois a três anos para o solo atingir seu equilíbrio (THEODORO, 2001).

Na Tabela 2, o peso médio das espigas com palha utilizadas foi de $(352,36 \mathrm{~g})$, sendo $(35,236 \mathrm{~kg})$ para 100 espigas, os pesos médios e totais, foram superiores aos relatados pela EMBRAPA (2017) com o milho verde BRS 3046 (29,100 kg), O rendimento das espigas despalhadas (22,540 kg ou 63,97\%), das palhas das espigas $(12,186 \mathrm{~kg}$ ou $34,58 \%)$ e dos grãos das espigas $(13,335 \mathrm{~kg}$ ou $37,84 \%)$ ficaram superiores aos descritos pela EMBRAPA (2017) que foram (17,800 kg ou $61,38 \%)$, (11,300 kg ou $38,97 \%)$ e $(7,200 \mathrm{~kg}$ ou $24,82 \%)$, respectivamente. Esse fato deve ter ocorrido pelos diferentes tratamentos usados nos estudos.

$\mathrm{Na}$ Tabela 3, encontra-se o valor médio de pH encontrado nos grãos de milho neste estudo foi de 6,68, observa o caráter de proximidade a alcalinidade. Logo, ocorreu uma pequena diferença quando comparado aos diferentes sistemas de cultivo da literatura, ou seja, o convencional e o orgânico (PINHO, 2008). O sistema de cultivo convencional apresentou o valor médio de pH 6,81, já o sistema de cultivo orgânico apresentou o valor médio de $\mathrm{pH}$ de 7,10. Pode-se observar que os dados foram relativamente próximos àqueles reportados na literatura para milho, o qual pode ser classificado como um alimento de baixa acidez (LEME, 2007).

O teor de sólidos solúveis totais encontrados, Tabela 3, o valor médio obtido foi de $6,10{ }^{\circ} \mathrm{Brix}$. Segundo Perfeito et al. (2017) verificaram que o fator cultivar influência os milhos doces SWB 551 e VIVI apresentaram valores médios de 15,83 e 14,50 ${ }^{\circ}$ Brix, respectivamente. Isto pode ser explicado pelo fato dos milhos doces possuírem distintas composições de açúcares nos grãos, o que thes conferem maior teor de sólidos solúveis (MATOS et al., 2008). O valor médio de acidez total titulável foi de 0,49 g/100 g ácido málico, Tabela 3. Perfeito et al. (2017) verificaram para milho doce fertirrigado valores de 1,11 a 1,46 g/100g.

A umidade em milho verde, segundo Cruz et al. (2002) as espigas devem ser colhidas quando estiverem com um teor de umidade entre 70 e $80 \%$. A média de teor de umidade encontrada foi de 64,38 $\mathrm{g} / 100 \mathrm{~g}$, Tabela 3. Perfeito et al. (2017) utilizaram quatro diferentes tratamentos de fertirrigação os valores médios de umidade ficaram entre 69,08 e 73,61 g/100g. Isso aconteceu porque as espigas obtiveram uma colheita tardia, diminuindo assim o seu teor de umidade. Todavia, para se ter espigas com a umidade desejada, a colheita deve ser realizada de forma antecipada.

O teor material mineral ou cinzas é o resíduo inorgânico que permanece após a queima da matéria orgânica, que é transformada em $\mathrm{CO}_{2}, \mathrm{H}_{2} \mathrm{O}$ e $\mathrm{NO}_{2}$ (ácidos orgânicos voláteis e semi-voláteis). Os elementos minerais apresentam nas cinzas sob a forma de óxidos, sulfatos, fosfatos, silicatos e cloretos, dependendo 
das condições de incineração e da composição dos alimentos (CECCHI, 2001).

A média das cinzas encontradas foi de 0,75 g/100g, Tabela 3. Perfeito et al. (2017) encontraram 1,89 g/100g para cinzas. Pinho (2008) verificaram o teor médio de cinzas de 0,60 g/100g. Segundo a Tabela Brasileira de Composição de Alimentos (TACO, 2011), o valor médio das cinzas deve ser de $(0,70 \mathrm{~g} / 100 \mathrm{~g})$.

Na Tabela, 3 encontra-se o teor de lipídios para o milho avaliado. Segundo Queiroz et al. (2010) os teores médios de lipídios foram de 4,70 g/100g. O teor médio de lipídios da TACO (2011) foi de 0,60 g/100g. Os teores médios de lipídios podem ter sido alterados devido o ataque de insetos, pragas, os quais têm preferência por se alimentarem do endosperma dos grãos, restando maior quantidade de pericarpo, fração com maior concentração de fibras insolúveis, e do gérmen, fração com maior teor de lipídeos e de cinzas (OLIVEIRA et al., 2011). Também as condições inadequadas de cultivo e armazenamento de milho podem proporcionar perdas no valor quantitativo e qualitativo dos grãos (SANTOS, 2008).

Os valores de proteínas foram de 4,59 g/100g. Entretanto, esse valor ficou abaixo do descrito na TACO (2011) (6,60 g/100g). Pinho (2008) obtiveram 2,40 g/100 de proteínas enquanto Ferrarini (2004) que avaliou 132 amostras de milho e encontrou uma variação de proteínas que vai de 7,66 g/100 a 13,12 g/100. Segundo Mazzuco (2002) a qualidade do milho varia de acordo com os híbridos utilizados por isso, as diferenças de cultivares também influenciam na qualidade nutritiva do grão. A qualidade dos grãos de milho pode ser afetada pela condição em que a planta foi cultivada, particularmente com relação à densidade no plantio.

O teor médio de carboidratos (Tabela 3$)(28,72 \mathrm{~g} / 100)$ das espigas, foi influenciado pelo sistema de cultivo. Em sistema convencional as espigas produzidas apresentaram valor médio de carboidrato maior que o produzido em sistema de cultivo orgânico. Pinho (2008) na análise de carboidratos entre variedades de milho produzidas em sistema convencional e orgânico foram de 12,97 e 16,77 g/100, respectivamente. Kokuszka (2005) a fotossíntese que é o fator responsável pela formação de carboidratos no grão e ocorre em maior intensidade nos grãos em sistema de cultivo convencional. Entretanto, os valores descritos por Pinho (2008), ficaram ligeiramente abaixo do encontrado neste trabalho, e no da TACO (2011) (28,6 g/100).

Os valores energéticos totais da amostra analisada foram de 147,19 kcal/100g (Tabela 3). Pinho (2008) encontraram valores inferiores em suas análises variando de 68,1 a $83,32 \mathrm{kcal} / 100 \mathrm{~g}$, ao avaliarem qualidade físico-química e sanitária de milho verde, cultivados em sistemas de produção orgânico e convencional. O sistema de cultivo influenciou nas características nutricionais dos grãos verdes de diferentes cultivares, especialmente quanto ao teor de valor energético total (Kcal), carboidratos e valor energético, havendo variações entre os diferentes cultivares.

Os valores médios obtidos para os parâmetros avaliados, somente o $\mathrm{pH}$ não teve diferença significativa ( $p>0,05)$ entre as três formulações de sucos F1, F2 e F3 (Tabela 4). Os parâmetros umidade, cinza e carboidratos, obtiveram os valores médios maiores na formulação F1 (Tabela 4). Quanto aos teores médios de sólidos solúveis totais (SST), lipídios e proteínas os valores foram superiores na formulação F3 (Tabela 4). Somente a acidez total titulável obteve valores maiores na formulação F2 (Tabela 4).

$\mathrm{O}$ pH não obteve alteração com a adição de leite de soja ou leite bovino. Cardoso et al. (2013) em 
seu estudo realizado com suco industrializado de uva, laranja, morango pronto para o consumo, observaram que, os sucos prontos para consumo obtiveram valores de $\mathrm{pH}$ menor (de 2,31 a 2,72), quando comparados aos sucos em pó (de 2,75 a 3,86). Porém, ambos apresentaram pH abaixo do encontrado nesse estudo (Tabela 4). Um pH de até 5,5, aproximadamente, é suficiente para enfraquecer e desmineralizar a superfície do esmalte dos dentes; no entanto para dentina (a mais interna das duas camadas calcificadas dos dentes), valores de $\mathrm{pH}$ 6,5, ou menor, tem o mesmo efeito maléfico, dependendo de outros fatores como a acidez titulável (CARDOSO et al., 2013).

Nos estudos realizados por Cavalcanti et al. (2006), os mesmos encontraram valores médios de sólidos solúveis totais que variaram de 10,23 a 13,53ํㅡrix em sucos prontos industrializados de maracujá, limão e manga. Os teores de sólidos solúveis totais analisados nesse estudo obtiveram diferenças significativas. Entretanto, as formulações F1 e F2 não houve diferença significativa (Tabela 4). Esse fato ocorreu devido o leite bovino possuir uma maior quantidade SST em relação ao leite de soja, como encontrado por Lima et al. (2009) na análise de leite integral e desnatado que variaram de 12,36 a 13,64 아ix e de 10,14 a 10,64 @Brix, respectivamente. Já, Pereira (2013) em seu estudo sobre o extrato de soja obteve valores médios entre 4,25 e 7,77 Brix no mesmo.

Os valores médios observados para a acidez total titulável (ATT) neste estudo (Tabela 4), estão acima dos valores médios encontrados em sucos de maracujá, morango, abacaxi, uva, laranja, limão e tangerina de 2,8 a 3,6 g/100g, sendo o de abacaxi de menor acidez Total Titulável e o de tangerina e limão com os maiores níveis de acidez total titulável. Nos estudos realizados por Silva et al. (2010) com sucos compostos de uva, foram encontrados valores médios que variaram de 0,10 a $0,33 \mathrm{~g} / 100 \mathrm{~g}$, valores estes bem a baixo dos encontrados neste trabalho (Tabela 4).

A umidade é um parâmetro muito importante dentro das análises, pois a quantidade de água encontrada em alimentos pode interferir no produto final (OLIVEIRA et al., 2017). Com relação aos valores médios de umidade (Tabela 4), foi observado que houve diferença significativa apenas entre F1 e F3 $(p<0,05)$ de suco de milho. Os valores ficaram próximos aos encontrados na TACO (2011), que foi de 85,4 g/100g.

Os teores de cinzas, o menor e maior valor observado foram para as formulações $F 2(0,57 \mathrm{~g} / 100 \mathrm{~g})$, F1 $(0,75 \mathrm{~g} / 100 \mathrm{~g})$, respectivamente. Houve diferença significativa para todas as formulações $(p<0,05)($ Tabela 9). Santana et al. (2009), em seu estudo realizado com suco de uva, encontraram valores médios de (0,22 a 0,39 g/100g). Na TACO (2011), para o suco de laranja, valores próximos foram verificados $(0,40 \mathrm{~g} / 100 \mathrm{~g})$.

O teor de lipídio das formulações de suco de milho F2 e F3 (Tabela 4), se aproximaram dos teores de lípidos encontrados por Brunelli et al. (2012), que foi de (1,05 a 1,46 g/100g) em seu estudo com bebida mista e soja. Branco et al. (2007), encontraram valores entre 0,89 e 1,46 g/100g. As diferenças encontradas na composição química do extrato hidrossolúvel de soja, podem ser devido a vários fatores tais como composição da matéria-prima e modo de processamento e metodologia de análise (BRUNELLI et al., 2012).

Assim como nos teores médios de lipídios, comportamento semelhante foram observados para os valores obtidos para as proteínas, com maiores médias para as formulações F2 e F3 (Tabela 4), estando dentro do padrão legal, que exige teor mínimo de 3\%. Somente o F1 ficou abaixo do padrão exigido. Branco 
et al. (2007), o teor de proteína (1,90 g/100g) encontrado foi inferior ao observado neste trabalho. A diferença na quantidade de proteína encontrada nas formulações F2, F3 para a formulação F1, pode ser explicada devido as duas formulações apresentarem adição de leite de soja e leite bovino, o que elevou significativamente o teor proteico dos sucos formulados.

Os teores de carboidratos obtidos neste referido trabalho ficaram bem acima dos encontrados por Brunelli et al. (2012), que foi respectivamente 3,29 g/100g, 3,64 g/100g e 3,38 g/100g. Isso pode ter acontecido possivelmente porque o milho (28,6 g/100g), segundo a TACO (2011), possui uma quantidade maior de carboidratos que a uva $(12,7 \mathrm{~g} / 100 \mathrm{~g})$, que foi o material de estudo de Brunelli et al. (2012). Os valores energéticos totais de cada amostra analisada foram observados uma faixa que vai de 67,37 a 87,44 $\mathrm{kcal} / 100 \mathrm{~g}$. A TACO (2011), determina valores que variam entre 45 a $51 \mathrm{kcal} / 100 \mathrm{~g}$ ) para suco de frutas como caju e laranja.

\section{CONCLUSÕES}

A caraterização física demonstrou o potencial de rendimentos industrial do milho doce. Os valores médios de cinzas, lipídios, proteínas, carboidratos e valor energético total, encontrados nos grãos de milho estiveram de acordo como o relatado na literatura. Somente sólidos solúveis e a acidez total titulável apresentaram valores acima da literatura. Algumas variações ocorreram devido ao tipo de sistema de cultivo diferentes dos realizados no referido estudo.

Os parâmetros avaliados nas três formulações de sucos houveram diferenças significativas entre as três formulações de sucos. Na formulação F1, obteve o maior teor de umidade, cinza e carboidratos. A F2, teve a maior acidez e o menor teor de cinzas. A partir disso, a F1 e F2 é uma alternativa para o público vegano ou intolerantes a lactose. Para a F3 apresentou o maior teor de pH, SST, proteína, lipídios e menor teor de umidade possuindo assim potencial para a comercialização pois apresenta maior vida de prateleira. Através deste estudo o suco de milho se apresentou como uma alternativa tecnológica viável para a agricultor familiar do município de Parauapebas/PA.

\section{REFERÊNCIAS}

ANDERSON, L.; DIBBLE, M V.; TURKKI, P. R.; MITCHEL, H. S.; RYNBERGEN, H. J.. Satisfazendo as normas nutricionais. In: Nutrição. 17 ed. Rio de Janeiro: Guanabara, 1988. p.66-71.

ANVISA. Agência Nacional de Vigilância Sanitária. Resolução RDC $\mathbf{n} . \mathbf{3 6 0}$, de 23 de dezembro de 2003. Aprova o

Regulamento Técnico sobre rotulagem nutricional de alimentos embalados. Brasília: DOU, 2003.

AOAC. Association of Official Analytical Chemists. Official methods of analysis of the Association of Official Analytical Chemists. 16 ed. Washington: AOAC, 1997.

BARBIERI, V. H. B.; LUZ, J. M. Q.; BRITO, C. H.; DUARTE, J. M.; GOMES, L. S.; SANTANA, D. G.. Produtividade e rendimento industrial de híbridos de milho doce em função de espaçamento e populações de plantas. Horticultura
Brasileira, Brasília, v.23, n.3, p.826-830, 2005. DOI: https://doi.org/10.1590/S0102-05362005000300027

BLIGH, E. C.; DYER, W. J.. A rapid method of total lipid and purification. Canadian Journal Biochemistry Physiology, Ottawa, v. 37, p. 911-917, 1959. DOI: http://doi.org/10.1139/059-099

BRANCO, I. G.; TEIXEIRA, A. M.; RIGO, M.; BEZERRA, J.R.M.V.; COUTINHO, M. R.; ARGANDOÑA, E. J. S.; BASTOS, R. G.. Avaliação da aceitabilidade sensorial de uma bebida à base de extrato hidrossolúvel de soja, polpa de morango e sacarose. Rev. Ciênc. Exatas Naturais, Guarapuava, v.9, n.1, p.129-141, 2007.

BRASIL. Resolução RDC n.259, de 20 de setembro de 2002. A Diretoria Colegiada da ANVISA/MS aprova o regulamento 
técnico para rotulagem de alimentos embalados. Brasília: DOU, 2002.

BRUNELLI, L. T.; VENTURINI FILHO, W. G.. Caracterização química e sensorial de bebida mista de soja e uva. Alim. Nutr., Araraquara, v.23, n.3, p.467-473, 2012.

CARDOSO, A. M. R.; SANTOS, A. M. S.; ALMEIDA, F. W. B.; ALBUQUERQUE, T. P.; XAVIER, A. F. C.; CAVALCANTI, A. L.. Características Físico-Químicas de Sucos de Frutas Industrializados: Estudo in vitro. Odonto, v.21, n.41-42, p.917, 2013. DOI: http://dx.doi.org/10.15603/21761000/odonto.v21n41-42p9-17

CAVALCANTI, A. L.; OLIVEIRA, K. F.; PAIVA, P. S.; RABELO, D. M. V.; COSTA, S. K. P.; VIEIRA, F. F.. Determinação de sólidos solúveis totais $\left(\right.$ Brix $\left.^{\circ}\right)$ e $\mathrm{pH}$ em bebidas lácteas e suco de frutas industrializados. Pesqui. Bras. Odontopediatria Clín. Integr., João Pessoa, n.6, v.1, p.57-64, 2006.

$\mathrm{CECCHI}, \mathrm{H}$. M.. Fundamentos teóricos e práticos em análise de alimentos. 2 ed. Campinas: UNICAMP, 2001.

CRUZ, J. C.; ALVARENGA, R. C.; NOVOTNY, E. H.; PEREIRA FILHO, I. A.; SANTANA, D. P.; PEREIRA, F. T. F.; HERNANI, L. C.. Cultivo do Milho: Sistema Plantio Direto. Sete Lagoas: MAPA, 2002.

EMBRAPA. Empresa Brasileira de Pesquisa Agropecuária. Milho e sorgo. Rio de Janeiro: EMBRAPA, 2017.

EMBRAPA. Sistemas de Produção: Cultivo do milho. 5 ed. Rio de Janeiro: EMBRAPA, 2009.

FAO. Food and Agriculture Organization of the United Nations. FAOSTAT. FAO, 2018.

KOKUSZKA, R.. Avaliação do teor nutricional de feijão e milho cultivados em sistemas de produção convencional e agroecológico na região Centro-Sul do Paraná. Dissertação (Mestrado em Agronomia) - Universidade Federal do Paraná, Curitiba, 2005.

LEME, A. C.. Avaliação e armazenamento de híbridos de milho verde visando a produção de pamonha. Dissertação (Mestrado em Ciência e Tecnologia de Alimentos) Universidade de São Paulo, Piracicaba, 2007.

LIMA, F. M.; BRUNINI, M. A.; MACIEL JÚNIOR, V. A.; MORANDIN, C. S.; RIBEIRO, C. T.. Qualidade de leite UHT Integral e desnatado, comercializado na cidade de São Joaquim da Barra, SP. Nucleus Animalium, Ituverava, v.1, p.61-69, 2009. DOI: http://dx.doi.org/10.3738/na.v1i1.255

MATOS, M. J. L. F.; TAVARES, S. A.; SANTOS, F. F.; MELO, M. F.; LANA, M. M.. Milho verde. EMBRAPA, 2008.

MAZZUCO, H.; LORINI, I.; BRUM, P. A. R.; ZANOTTO, D. L.; JUNIOR, W. B.; AVILA, V. S.. Composição Química e Energética do Milho com Diversos Níveis de Umidade na Colheita e Diferentes Temperaturas de Secagem para Frangos de Corte. R. Bras. Zootec., Piracicaba, v.31, n.6, p.2216-2220, 2002. DOI: http://doi.org/10.1590/S151635982002000900009

OLIVEIRA JUNIOR, L. F. G.; DELIZA, R.; BRESSAN-SMITH, R.; PEREIRA, M. G.; CHIQUIERE, T. B.. Seleção de genótipos de milho mais promissores para o consumo in natura. Ciênc.

Tecnol. Aliment., Campinas, v.26, n.1, p.159-165, 2006. DOI: http://doi.org/10.1590/S0101-20612006000100026

OLIVEIRA, J. F.; GARCIA, L. N. H.; PASTORE, V. A. A.; RAGHIANTE, F.; POSSEBON, F. S.; PINTO, J. P. A. N.; MARTINS, O. A.. Qualidade de iogurtes de coco e morango. Revista Brasileira de Higiene e Sanidade Animal, Fortaleza, v.11, n.4, p.416-425, 2017.

OLIVEIRA, P.; KLUTHCOUSKI, J.; FAVARIN, J. L.; SANTOS, D. C.. Consórcio de milho com braquiária e guandu-anão em sistema de dessecação parcial. Pesquisa Agropecuária Brasileira, Brasília, v.46, n.10, p.11841192, 2011. DOI: http://doi.org/10.1590/S0100-204X2011001000010

PAES, M. C. D.; ALMEIDA, A. C.; COSTA, C. A.; PINHO, L.. Qualidade de milho verde cultivado em sistema de produção orgânico e convencional. Revista Brasileira de Milho e Sorgo, Sete Lagoas, v.7, n.3, p.279-290, 2008. DOI: http://dx.doi.org/10.18512/1980-6477/rbms.v7n3p279-290

PEREIRA FILHO, I. A.; CRUZ, J. C.. Cultivo do milho. Plantio, espaçamento, densidade, qualidade de sementes. Sete Lagoas: Embrapa milho e sorgo, 2002.

PEREIRA, D. G.. Obtenção do extrato de soja e okara por diferentes métodos. Monografia (Tecnólogo) -Universidade Tecnológica Federal do Paraná, Londrina, 2013.

PERFEITO, D. G. A.; LOPES, M. C. M.; SALOMÃO, L. C.; DE SOUZA, M. L.; BENETT, C. G. S.; LIMA, B. P.. Caracterização pós-colheita de milho doce submetido ao parcelamento de fertirrigação nitrogenada. Braz. J. Food Technol., Campinas, v.20, p. e2016140, 2017. DOI: http://doi.org/10.1590/19816723.14016

PINHO, L.. Qualidade físico-química e sanitária de tomate cereja e milho verde, cultivados em sistemas de produção orgânico e convencional. Dissertação (Mestrado) Universidade Federal de Minas Gerais, Montes Claros, 2008.

QUEIROZ, V. A. V.; CARVALHO, A. C. R.; MENDES, S. M.; SIMEONE, M. L. F.; ALVES, G. L. O.. Alterações na composição nutricional de milho durante o armazenamento em paióis. In: CONGRESSO NACIONAL DE MILHO E SORGO, 28. Anais. Goiânia, 2010.

SANTANA, C. V. C.. Físicas do solo, no sistema plantio direto, em resposta a aplicação de fertilizante organomineral. Dissertação (Mestrado em Ciências Agronômicas) - Universidade Estadual Paulista, Botucatu, 2012.

SANTANA, I.; CABRAL, L. M. C.; FREITAS, S. C.; FREITASA, A. O.; MATTA, V. M.; PEREIRA, S.. Composição química e centesimal de suco de uva concentrado por osmose inversa: influência da temperatura do processo. Rio de Janeiro: Universidade Federal do Rio de Janeiro, 2009.

SANTOS, I. C.; MIRANDA, G. V.; MELO, A. V.; MATOS, R. N.; OLIVEIRA, L. R.; LIMA, J. S.; GALVÃO, J. C. C.. Comportamento de cultivares de milho produzidos organicamente e correlações entre características das espigas colhidas no estádio verde. Revista Brasileira de Milho e Sorgo, Sete Lagoas, v.4, n.1, p.45-53, 2005. 
SANTOS, J. P.. Controle de pragas durante o armazenamento de milho. In: CRUZ, J. C.; KARAM, D.; MONTEIRO, M. A. R.; MAGALHÃES, P. C.. A cultura do milho. Sete Lagoas: Embrapa Milho e Sorgo, 2008. p.25-302.

SAS INSTITUTE. SAS for Windows, versão 9.4 SAS $^{\bullet}$ : SAS User guide. Carry, 2013.

SILVA, T. A. A.; SAMPAIO C. S.; SANTOS, J. E. A. F.; ABÍLIO, G. M. F.; XAVIER, A. F. C.; CAVALCANTI, A. L.. Avaliação do Potencial Erosivo de Bebidas à Base de Soja. Revista Brasileira de Ciências da Saúde, João Pessoa, v.14, n.1, p.109-114, 2010. DOI:

http://doi.org/10.4034/RBCS.2010.14.01.13

STRIEDER, M. L.. Resposta do milho à redução do espaçamento entrelinhas em diferentes sistemas de manejo. Dissertação (Mestrado em Agronomia) -
Universidade Federal do Rio Grande do Sul, Porto Alegre, 2006.

TACO. Tabela Brasileira de Composição de Alimentos. 4 ed. Campinas: UNICAMP, 2011

THEODORO, V. C. A.. Caracterização de produção do café orgânico, em conversão e convencional. Dissertação (Mestrado em Agronomia/Fitotecnia) - Universidade Federal de Lavras, Lavras, 2001.

VASCONCELOS, M. C.; BENNETT, R.; CASTRO, C.; CARDOSO, P.; SAAVEDRA, M. J.; ROSA, E. A.. Study of Composition, Stabilization and Processing of Wheat Germ and Maize Industrial By-Products. Industrial Crops and Products, v.42, 292-298, 2013. DOI:

http://dx.doi.org/10.1016/j.indcrop.2012.06.007

A CBPC - Companhia Brasileira de Produção Científica (CNPJ: 11.221.422/0001-03) detém os direitos materiais desta publicação. Os direitos referem-se à publicação do trabalho em qualquer parte do mundo, incluindo os direitos às renovações, expansões e disseminações da contribuição, bem como outros direitos subsidiários. Todos os trabalhos publicados eletronicamente poderão posteriormente ser publicados em coletâneas impressas sob coordenação da Sustenere Publishing, da Companhia Brasileira de Produção Científica e seus parceiros autorizados. Os (as) autores (as) preservam os direitos autorais, mas não têm permissão para a publicação da contribuição em outro meio, impresso ou digital, em português ou em tradução. 